Témoigner Témoigner. Entre histoire et mémoire

Getuigen Revue pluridisciplinaire de la Fondation Auschwitz

$122 \mid 2016$

Révisionisme et négationisme

\title{
Dieren en de oorlog
}

Les animaux et la guerre

\section{Frédéric Crahay}

Traducteur : Gorik de Henau

\section{(2) OpenEdition}

\section{Journals}

Édition électronique

URL : https://journals.openedition.org/temoigner/4048

DOI : $10.4000 /$ temoigner.4048

ISSN : 2506-6390

Éditeur :

Éditions du Centre d'études et de documentation Mémoire d'Auschwitz, Éditions Kimé

Édition imprimée

Date de publication : 2 mai 2016

Pagination : 5-7

ISSN : 2031-4183

Référence électronique

Frédéric Crahay, «Dieren en de oorlog», Témoigner. Entre histoire et mémoire [Online], 122 | 2016, Online op 30 septembre 2021, geraadpleegd op 13 janvier 2022. URL: http://journals.openedition.org/ temoigner/4048 ; DOI: https://doi.org/10.4000/temoigner.4048 


\section{DIEREN \\ EN DE OORLOG}

TENTOONSTELLING Een bijzonder perspectief op oorlogsvoering in het Doornikse Natuurhistorisch museum en Vivarium.

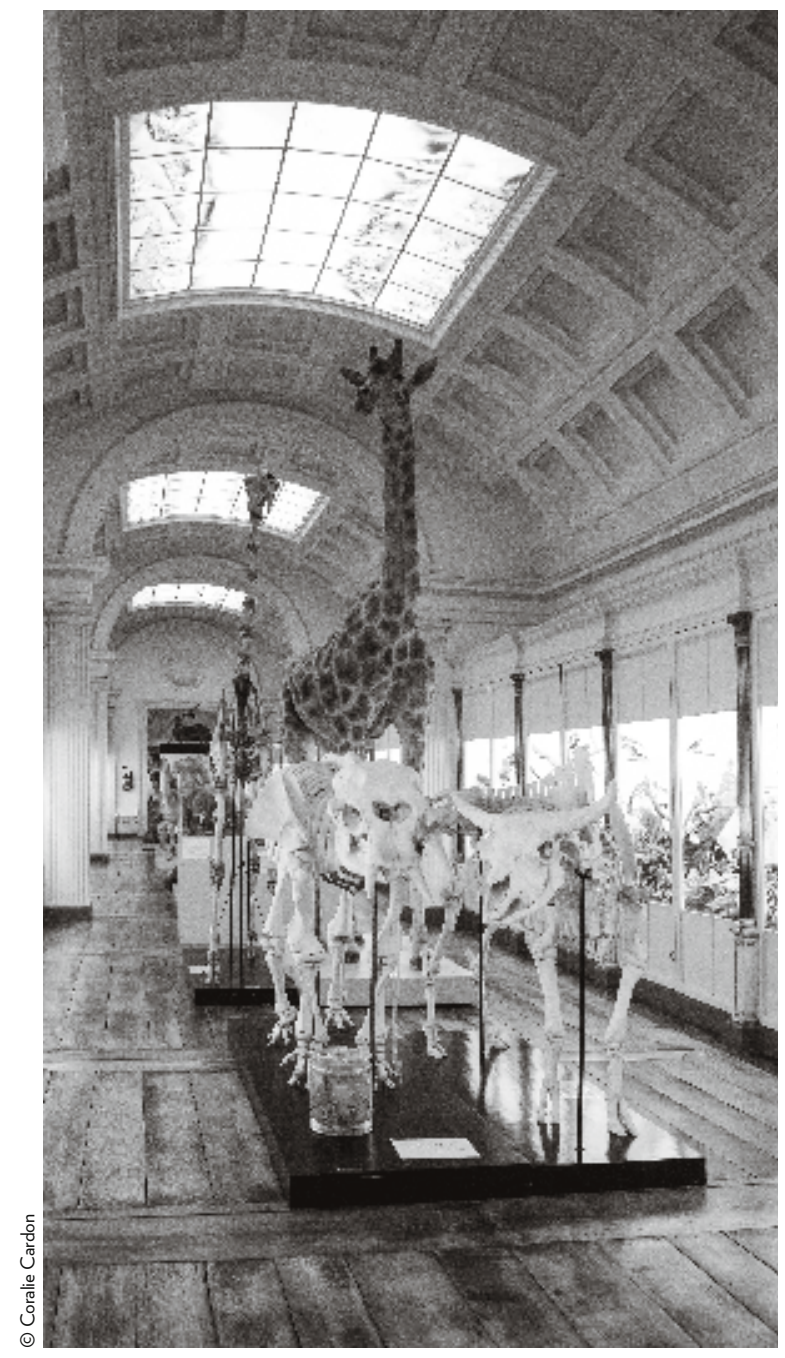

A priori is het een vreemd idee om een tentoonstelling te wijden aan dieren en oorlog. In het collectief geheugen lijken die twee op het eerste gezicht geen verband met elkaar te houden, want de krijgskunst, en vooral de intentie om ten oorlog te trekken, blijven gewoonlijk beperkt tot de mens. Wat hebben andere dieren dan te maken met de broederstrijd die de homo sapiens sinds mensenheugenis voert? Het ogenblik is wel degelijk oordeelkundig gekozen. Sinds augustus 2014 zijn de herdenkingen van de Eerste Wereldoorlog niet van de lucht, dus waarom geen hulde brengen aan de dieren die net zo goed het slachtoffer waren van de menselijke waanzin. Het idee om de dieren die voor het vaderland sneuvelden in de schijnwerpers te plaatsen is tenslotte niet nieuw: sinds 1931 heeft Brussel een 'Monument voor de oorlogsduif'. Dit werk van Victor Voets en Georges Hano drukt de erkentelijkheid uit van het vaderland voor de duif; tegelijk eert het de duivenliefhebbers die tijdens de Duitse bezetting van 1914 tot 1918 hun leven waagden door boodschappen over de frontlinie te sturen - een vorm van verzet die hun vaak het leven kostte.

Over die oorlogsduiven gaat de tentoonstelling in het Musée d'Histoire naturelle in Doornik, maar ook over dieren die in de loop der tijden tijdens gewapende conflicten werden ingezet, zowel vanwege de specifieke eigenschappen van hun soort als vanwege de dodelijke kracht die ze kunnen ontwikkelen.

De tentoonstelling vindt plaats op een majestueuze plek. Het museum is klein, maar heeft de charme van een negentiende-eeuws rariteitenkabinet. De lichte formolgeur doet denken aan de galerieën met opgezette dieren die in de jaren 1800 bij de aanvang van de moderne wetenschap het licht zagen. Sinds 1839 verwelkomt het museum in Doornik de liefhebbers van de natuurlijke historie en de kunst van de taxidermie, die er momenteel op achteruitgaat. De taxonomie van het dierenrijk wordt vrij summier uitgelegd via de goed verlichte uitstalkasten, waarin een deel van de collectie $\bullet \bullet$ 


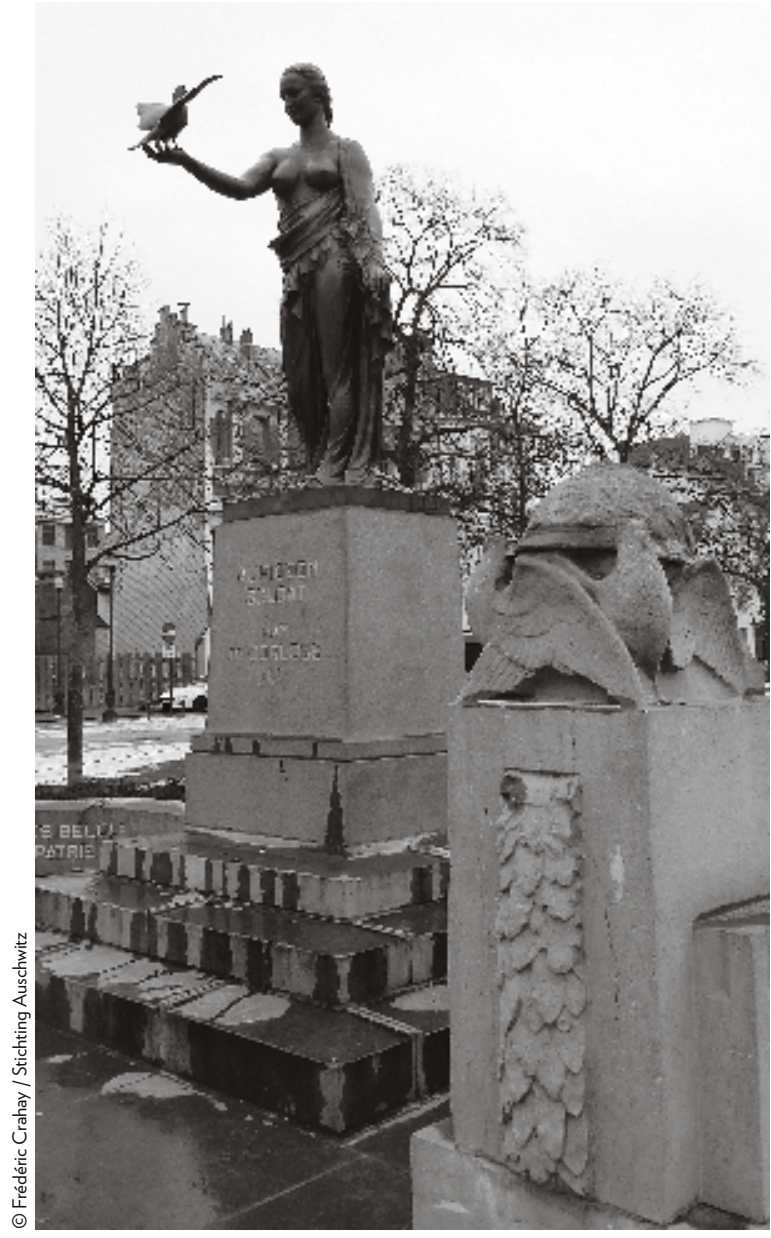

_ Monument voor de oorlogsduif, opgericht in 1931 in Brussel. Een kunstwerk van Victor Voets en Georges Hano.

$\bullet \bullet$ is te zien. Het overzichtsluik wordt treffend vervolledigd met een vivarium voor reptielen.

Voorbij de permanente tentoonstelling staat de bezoeker plotseling oog in oog met twee gevechtsolifanten, het startpunt van de nieuwe expositie. Al sinds de oudheid worden de dikhuiden gebruikt om de getalsterkte van legers te verhogen. Dat gebeurde onder andere tijdens de slag bij Gaugamela in 331 voor Christus (Remy 2015), toen Alexander de Grote vijftien gevechtsolifanten buitmaakte op het leger van Darius III van Perzië. Maar ook de legers van Pyrr- hus, koning van Epirus in 279 voor Christus, deden beroep op de dieren, en natuurlijk de Carthaagse generaal Hannibal, die tijdens de Tweede Punische Oorlog (218-201 voor Christus) de Alpen overstak. $\mathrm{Na}$ de ronduit strijdvaardige aanloop van de tentoonstelling verschuift het accent naar dieren die de mens als wacht bijstaan. Honden vormen daarvan het beste voorbeeld, maar we denken niet zo vaak aan meeuwen die de periscopen van onderzeeërs opsporen, of aan zeezoogdieren als waterwachters. In 390 voor Christus behoedden de ganzen van het Capitool de Urbs met hun gesnater voor een aanval van de Galliërs, aldus een Romeinse legende. Maar de bezoeker met interesse voor de Holocaust denkt onwillekeurig aan de ganzen die in Sobibór het geschreeuw overstemden van de ongelukkigen die stikten in de gaskamers. In zijn documentaire Sobibor, 14 octobre 1943, 16 heures verwijst Claude Lanzmann er meermaals naar, via shots van een rondzwermende troep ganzen (Lanzmann 2001).

De tentoonstelling Dieren en de oorlog omvat een aantal hoofdstukken over diverse aspecten van de band tussen mens en dier. Dieren kunnen nuttig zijn voor mensen, zoals toen duiven tijdens de Eerste Wereldoorlog boodschappen overbrachten, en soms betekenen ze onze redding. Zo worden tegenwoordig marterachtigen gebruikt om antipersoonsmijnen op te sporen; die kunnen dan worden opgeruimd, zodat de akkers weer vruchten voortbrengen in 's werelds contreien waar zulks hoogdringend is. De Belgische niet-gouvernementele organisatie $\mathrm{APOPO}^{1}$ leidt trouwens gambiahamsterratten op in de strijd tegen mijnen, maar ook om gevallen van tuberculose op te sporen in verschillende regio's in de wereld. Een ander aspect van de mens-dierrelatie is van psychologische aard, want in de extreme context van gewapende conflicten bieden dieren vaak de enige vorm van troost. Het gebeurt wel eens dat soldatencompagnieën een dier tot mascotte verheffen, naar het voorbeeld van de beer die tijdens de Tweede Wereldoorlog door een Poolse artilleriecompagnie Wojtek werd gedoopt. Bekender nog is Winnie-the-Pooh, die beroemd werd dankzij Disney. Dit goedmoedige personage gaat terug op een echte zwarte beer, Winnipeg, die tijdens de Eerste Wereldoorlog actief was aan het westelijke front. Een van de sterke punten van de tentoonstelling is dat ze

(1) https://www.apopo.org/en/ (geraadpleegd 14 december 2015). 


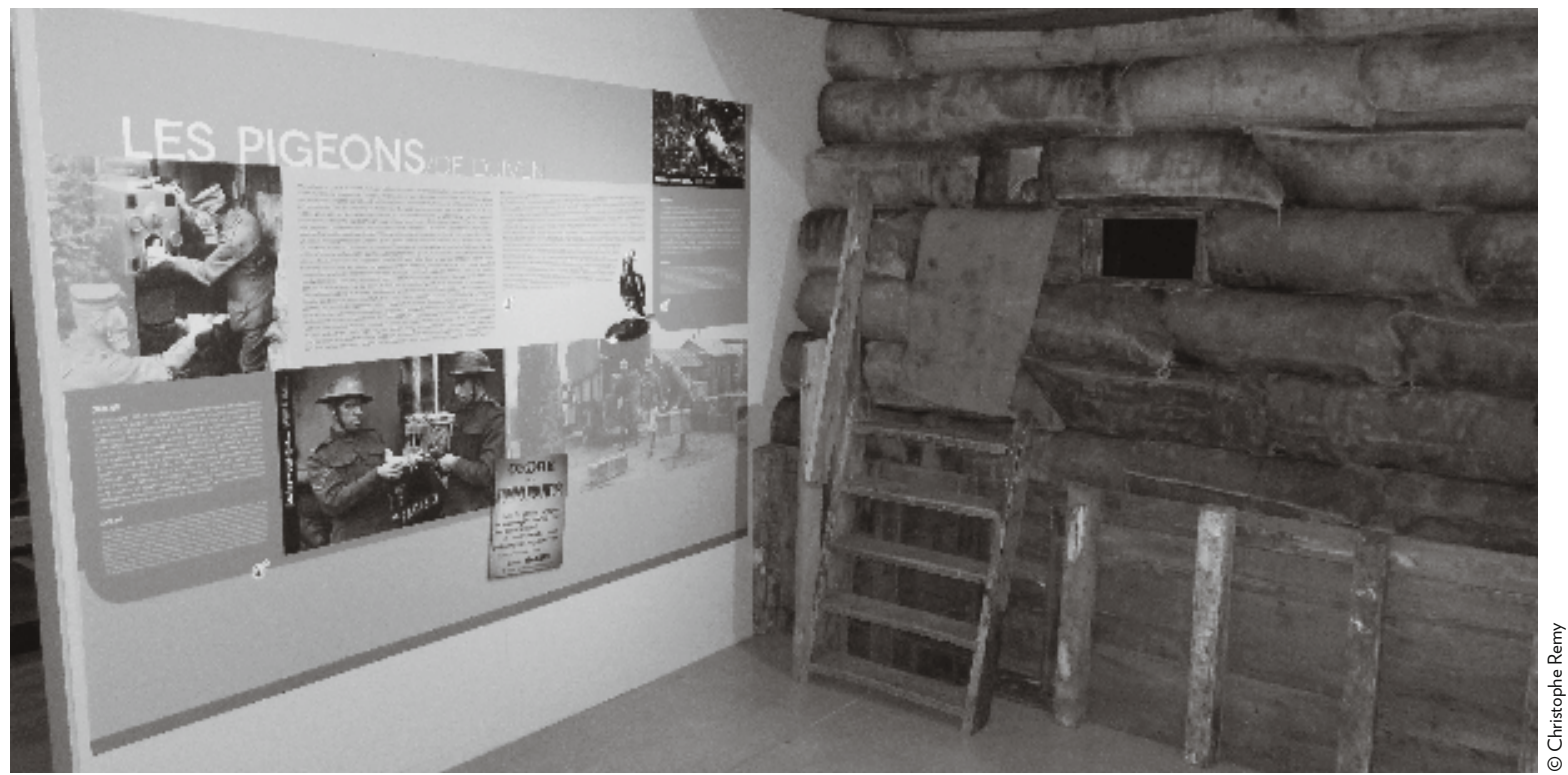

terecht de nadruk legt op de mens-dierverhouding en op traumatische gebeurtenissen, zoals de wereldoorlogen, in het collectief geheugen. Er gaat veel aandacht naar de Eerste Wereldoorlog en de verhouding tussen de poilus (soldaten) en hun vrienden (duiven, paarden, honden en katten) of vijanden (ratten, luizen en vlooien). Tijdens dit conflict, de eerste moderne oorlog, leden in het bijzonder de paarden grote verliezen. Er waren naar schatting zes miljoen paarden betrokken; het grootste deel daarvan overleefde het niet, aangezien in het tijdperk van de mitrailleurs charges van de cavalerie niet echt gepast meer waren. Vervolgens zou het paard vooral worden ingezet als logistiek hulpmiddel, waardoor wegen die ontoegankelijk waren voor voertuigen toch begaanbaar bleven. De bezoeker herinnert zich ook de foto's van Hitler aan het front met zijn foxterriër Fuchsl.

Een ander sterk punt van de tentoonstelling is de erg concrete representatie van een veeleer naargeestig thema, met behulp van opgezette dieren uit de museumcollectie. Zo wordt het onderwerp inzichtelijk voor een jong publiek. Ook de ecologisch gemotiveerde toeschouwer komt aan zijn trekken, want er is aandacht voor de gevolgen van menselijke conflicten op de fauna en flora van een aantal landen. Zo moest het nationale park Virunga in de Democratische Republiek Congo de tol betalen voor meer dan 25 jaar conflicten in de regio. Wat verder terug in de tijd liet de Vietnamoorlog niet alleen littekens achter bij de bevolking, maar ook in de bossen die tijdens operatie Ranch Hand met ontbladeringsmiddelen werden besproeid om zo de Vietcongstrijders hun schuilplaats in de jungle te ontnemen. De ecologische ramp ging in dat specifieke geval ook gepaard met een humanitair drama, waarbij ongeveer 2,1 miljoen mensen het leven lieten.

De tentoonstelling Dieren en de oorlog, met een duidelijk en bondig verhaal, biedt heel wat originele pedagogische mogelijkheden. Ze werd wegens succes verlengd en is nog te zien tot in juni 2016.

Frédéric Crahay

Vertaling: Gorik de Henau

\section{Meer weten}

Natuurhistorisch museum en Vivarium. Cour d'honneur de l'Hôtel de Ville, rue Saint-Martin, 52, 7500 Doornik. Van 6 december 2014 tot 30 juni 2016.

\section{Bibliografie}

Claude Lanzmann, Sobibor, 14 oktober 1943, 16 uur, Frankrijk, 2001, 95 min.

Christophe Remy, Les animaux et la guerre/Dieren en oorlog, Doornik: Natuurhistorisch museum, 2015. 